\title{
Dan Graham e a Cidade Contemporânea Dispositivos espaciais, comportamentos e relações de poder
}

\author{
> Fábio Lopes de Souza Santos \\ Universidade de São Paulo, Brasil \\ sotosantos@uol.com.br
}

\author{
> Rafael Goffinet de Almeida \\ Universidade de São Paulo, Brasil \\ rafael.goffinet.almeida@usp.br
}

\begin{abstract}
Dan Graham became an important reference in contemporary art developing since the 1960's a series of works that maintain a profound relation with urban cultural phenomena. This article proposes the analysis of his works produced over the 1970's and 1980's which presents the use of technical supports like video, exhibition and surveillance systems and which guided his earlier aesthetic research - related to the "institutional critique" - to the investigations about the power relations between objects, public and the space where they are placed.
\end{abstract}

Keywords: Dan Graham; Contemporary Art; Contemporary Architecture; Contemporary City; Contemporary Spatiality.

A trajetória do artista norte americano Dan Graham, iniciada em 1965, é bastante representativa do desenvolvimento da arte contemporânea marcado pela superação de códigos e convençôes que determinavam a produçáo do objeto de arte, suas formas de inserção e os significados a ele atribuídos dentro do chamado circuito institucional da arte. Através da produção de artigos em revistas, performances, instalaçóes com o uso de vídeo, vidro e espelho, uma constante produção de textos e seus mais recentes dispositivos espaciais, Graham parte da chamada "crítica institucional" da arte, questionando as concepçóes de autonomia e objetividade da arte de ponta até entáo, para lançar-se à pesquisa sobre as relaçóes entre objeto, público e o espaço em que estão inseridos. Aos poucos, constrói uma sólida investigação acerca dos processos de percepção e de comportamento do público, promovida, a princípio dentro, dos espaços protegidos da arte para, em seguida, inseri-la sobre uma série de situaçóes mais propriamente urbanas.

Boa parte deste conjunto, produzido entre as décadas de $1970 \mathrm{e}$ 1980, marca o uso de meios técnicos como projeçóes, vídeo, sistemas de exibição e vigilância buscando reorganizar as formas de exibição e de representação através de tensóes sobre os modos de exibição definidos pelo objeto artístico e conseqüentemente sobre os modos de percepção do público. Interessa ao artista lidar com as relaçôes com que o espectador (no limite, o habitante da cidade) estabelece com o campo social que o cerca (seja dentro do espaço expositivo ou fora dele), fazendo emergir através destas obras processos de construçáo de subjetividades e relaçóes de poder agindo sobre seu comportamento e sua percepção.
Buscando aprofundar a compreensão deste olhar do artista sobre a arquitetura e a cidade, aproveitaremos o fato de Dan Graham ser um leitor de Michel Foucault para traçar algumas aproximaçóes entre as questóes identificadas nesse conjunto de obras do artista ás reflexôes do importante autor presentes em sua hipótese sobre o "poder disciplinar". Nela estáo presentes questóes relacionadas ás instituiçôes e ao desenvolvimento de "dispositivos de poder" determinando comportamentos, hábitos e a própria consciência do sujeito inaugurado pela modernidade. Tal como Graham descreve em um de seus artigos, Foucault lança a perspectiva da forma espacial como um fator decisivo para se estabelecer um sistema de hierarquias de funções e posiçóes para o exercício de determinada ordem através, por exemplo, de "espaços enclausurados (escola, fábrica, convento, prisão), uma organização geométrica celular (salas de aula, patamares, grades), um sistema uniforme de divisão temporal (grade horária) e uma situação ótica que permita total vigilância de todos os indivíduos” (GRAHAM, 1981, p.58).

Ao descrever o "poder disciplinar", Foucault retrata o desenvolvimento de forças políticas se estendendo ao nível dos corpos individuais como um mecanismo de controle e dominação operando em duas escalas: a de ordem microcósmica, vigiando e determinando o tempo, o comportamento, os hábitos dos indivíduos; e a de ordem macrocósmica, a partir do momento em que a somatória desses corpos acaba totalizando um grupo social amplamente controlado. Neste sentido, o autor demonstra como uma condição social é imposta por meio de uma vinculação através de instrumentos desenvolvidos pelas várias instituiçóes que organizam a vida política 
e social, como a religiosa, a psiquiátrica, a escolar, a militar e, a partir delas, as organizaçóes fabris e a própria ordem territorial urbana.

Desta perspectiva, as instituiçôes são encaradas como um aparato de relaçóes suficientemente complexas pelas quais toda uma ordem de valores e códigos sociais e políticos deverão ser exercidos em sua plenitude. Contrariando o pensamento que as enxerga como a origem de determinada organizaçáo social e de poder, Foucault reclama uma inversão do ponto a partir do qual é preciso analisálas. Ao invés de debruçar-se sobre as partes e segmentaçóes que as organizam, cada elemento, posição e função nela distribuída (as suas "regularidades") deve-se perceber as relaçôes que se configuram através dessas disposiçóes: as instituiçôes devem ser tomadas como objetos a partir dos quais é possível projetar críticas e reflexóes mais amplas.

Algo que se faz presente em parte da crítica ao circuito institucional da arte, revelando, como afirma Graham, os "significados ideológicos e posiçôes que regulam e contém as experiências subjetivas” de seu público (GRAHAM, 2009, p.11). Museus e galerias, constituindo-se historicamente como os espaços privilegiados de exibição de arte, funcionam como verdadeiras "oficinas corporativas" agindo politicamente através da exportação de valores culturais, como constatado através das açóes organizadas pelas grandes instituiçóes de arte e cultura durante os anos de 1940 e 1950 para o desenvolvimento de um establishment cultural em torno da produçáo de arte moderna americana.

Posicionamento refletido em uma produção artística cujo enfoque recai sobre as estruturas implícitas do espaço de expositivo pautando a relaçáo entre o observador e a obra. É neste momento em que Graham lança máo de meios técnicos para provocar uma tensão nos modos de exibição definidos pelo objeto artístico e conseqüentemente sobre os modos de percepção do público.

Figura 1: (esq.) Performer/Audience/Mirror, 1975; (dir.) Public spaces/Two Audiences, 1976.

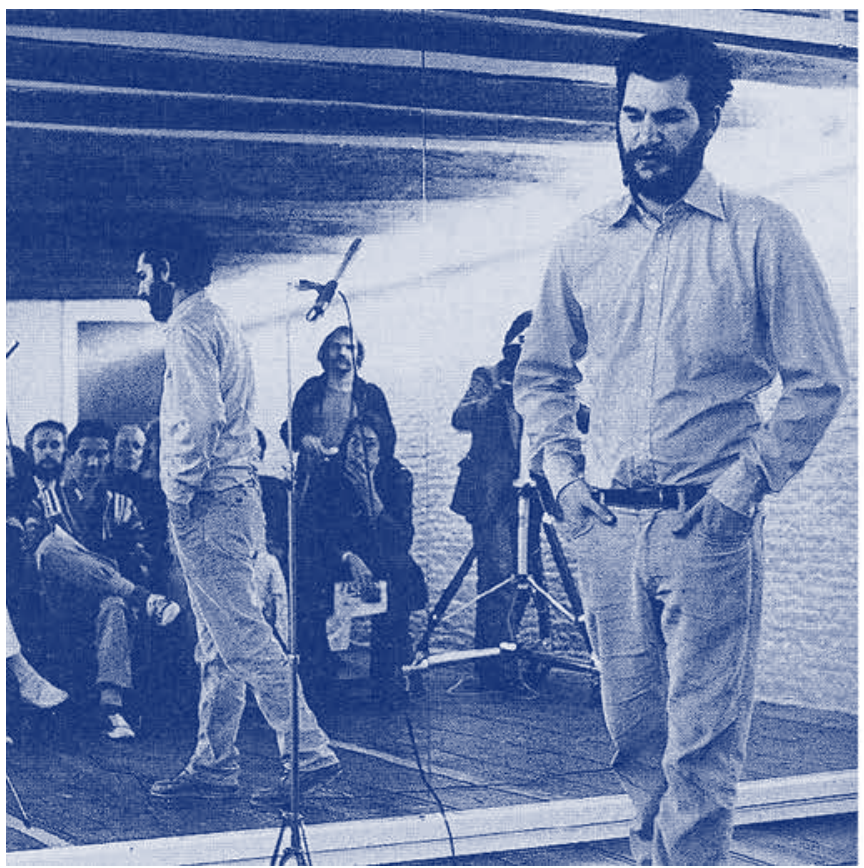

A propósito dessas relaçóes, Foucault enxergava nas instituiçóes o desenvolvimento de uma série de atividades funcionando como exercícios em que, através do envolvimento exaustivo do corpo, seria capaz de projetar na consciência dos indivíduos o seu objetivo máximo da disciplina, isto é, devido a um processo de vigilância permanente, porque virtualizada, o indivíduo responderia afirmativamente por conta própria a ordem que lhe é imposta, produzindo o que Foucault chamou de "corpos sujeitados" (FOUCAULT, 2006, p.70). Para Graham, uma forma de se esquivar desses procedimentos perpetrados pelo "cubo branco" de construção de uma subjetividade, da programação do que e de como deve ser apreendido, seria justamente promover tensóes nas disposiçôes convencionalmente determinadas pelo espaço, mostrando "as pessoas percebendo a si mesmas como elas se percebem no lugar do objeto de arte" (GRAHAM, D. 1990, p. 143).

Seu conjunto de performances, desenvolvido na primeira metade da década de 1970, marca, além da introdução do corpo,o uso de projeçóes e vídeospara construir efeitos nos modos de representação da imagem e destes no tempo. Em Performer/Audience/Mirror, realizada em 1975, a figura do artista/performer aparece dominando o palco de um auditório que separava a plateia de um enorme espelho posicionado às suas costas. Sua presença funcionava como um mediador do público em confronto com sua própria imagem: dividida em quatro blocos de cinco minutos, "o artista se descrevia; depois descrevia o público; depois, virando para o espelho, descrevia sua imagem seguida por uma análise da imagem refletida dopúblico" (COLOMINA; FRANK; PELZER, 2001, p.50). Através dessa articulação entre espaço e imagens (visuais e orais), Graham colocava a (auto-)percepção do público em constante alteração, sendo construída e reconstruída, confrontando-se com o mecanismo de construçáo de subjetividade imposto pelo espaço expositivo.

Aos poucos, as performances permitiram-no amadurecer o mecanismo que ativa a "recepçáo" da obra de arte a ponto de

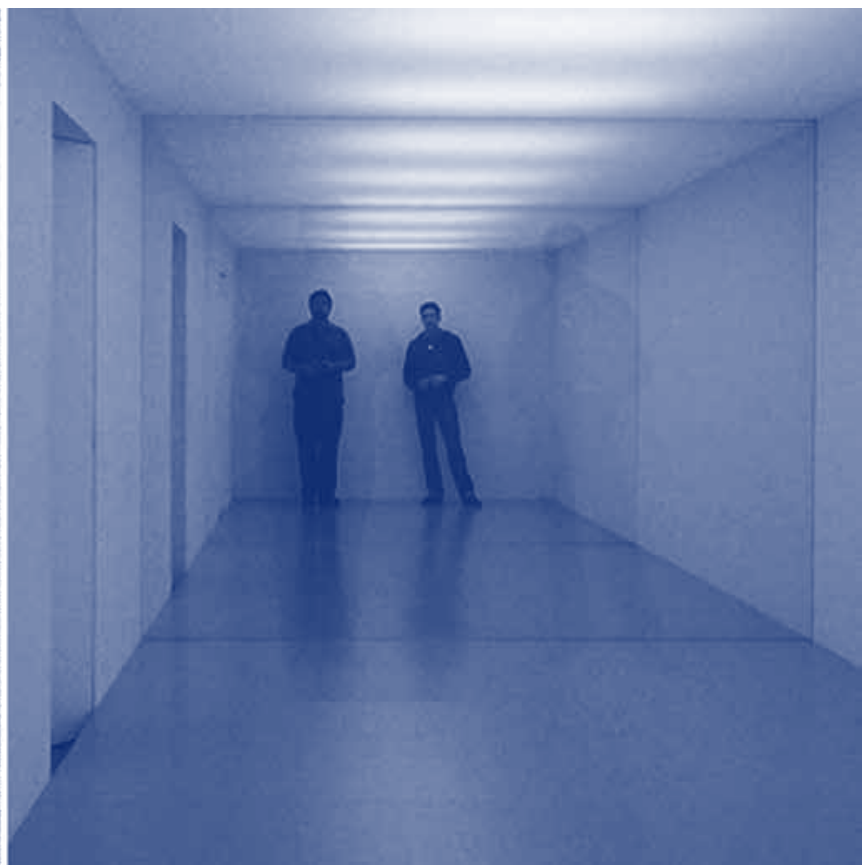


conduzir à investigaçáo da própria condição do espectador. $\mathrm{O}$ passo seguinte foi construir situaçóes que dispensassem a presença do artista durante este processo, de modo que a própria presença do público ativasse as relaçóes de intersubjetividade: instalaçóes determinando percursos espaciais pontuados por vídeos, reflexos de espelho e da transparência do vidro, mantendo o enfoque sobre a percepção e a reação do visitante, individual e coletivamente.

Em Public Spaces/Two Audiences, produzida em 1976, através da articulação entre paredes opacas, planos de vidro e de espelhos, o artista construiu duas salas onde o visitante, ao percorrê-las, se deparava com a exibição de sua própria imagem sobreposta às imagens ou mesmo à presença dos demais observadores naquele instante. Separadas por um plano de vidro com certo grau de opacidade e transparência, além dos planos espelhados localizados ao fundo de cada sala, encerrando-as, estes ambientes promoviam forte abalo na dimensão temporal e, sobretudo, espacial percebida pelo observador, amplificando seus modos de apreensão, de apropriação e de interaçáo.

A obrarepresenta a descoberta de Graham de um campo de pesquisa sobre o comportamento e os modos de percepção do público a partir de elementos e dispositivos próprios da arquitetura. Não tardou para que Graham percebesse estas instalações como projetos de espaços onde se tornava possível lidar não somente com o desempenho social do público como também do próprio dispositivo espacial. A esta altura, tomava consciência de que os elementos constitutivos do espaço também exercem grande influência sobre os modos como o público irá se relacionar, guardando uma carga de propriedades objetivas e significados subjetivos responsáveis por condicionar a experiência daqueles ali presentes. $O$ passo seguinte foi deslocar tal descoberta desde o espaço protegido da arte para outros lugares, corroborando sua tese de que "o museu e a cidade são a mesma coisa” (GRAHAM, D. 1990, p.143), isto é, o espaço expositivo era mais um entre tantos outros equipamentos operando e organizando a totalidade do espaço urbano.

Graham iniciava neste momento uma peculiar operação dentro do conceito de "dispositivo" trabalhado por Foucault, cuja definição aponta para a criaçáo de instrumentos capazes de envolver os homens em uma sucessão de exercícios fundamentais para "detalhar ao longo de uma escala temporal o crescimento e o aperfeiçoamento da disciplina” (FOUCAULT, 2006, p.59), de um desempenho social politicamente determinado. A este universo de sistemas e mecanismo, representados ao longo da história pelo surgimento de jogos e exercícios corporais, supervisionados por uma inteligência cada vez mais complexa de codificaçáo, de transferência da informação para uma individualização esquemática e centralizada dos corpos e, por fim, potencializadas por uma vinculação espacial, a todos esses recursos táticos específicos de controle e dominação, Foucault deu o nome de "dispositivos de poder".

O Panóptico de Bentham, originado no século XVIII, é bastante exemplar. Após uma descrição de cada compartimento, de cada elemento dessa "estrutura ideal" a qualquer instituição, como dizia Bentham, e da relação funcional e espacial que mantém, Foucault lança a pergunta: "o que quer dizer esse esquema?". Trata-se de uma questấo chave para este estudo, na medida em que chama atenção para a importância do espaço como um fator decisivo na construção de determinada relação social. Diante da disposição dos compartimentos individuais circundando um espaço comum e da presença de uma torre erguendo acima e no centro deste conjunto uma sala visualmente protegida, Foucault destaca: a individualizaçâo do grupo que ali deveria ser recluído, distribuído e organizado em unidades isoladas; a centralizaçáo do controle operado com o devido distanciamento; a vigilância permanente, total e invisível; a desindividualização do poder, que protegido dos olhares se mantém anônimo e virtual. Dessa maneira, o Panóptico funcionaria como uma idealização da vinculação espacial indispensável para a açáo do poder sobre o corpo, adquirindo completo saber sobre ele, controlando e conduzindo seu desenvolvimento no tempo e no espaço.

Neste sentido,valeria ainda pensar umavinculação espacial do poder em escalas maiores, incluídas aí a própria cidade, onde o esquema desenvolvido por Bentham se desdobraria em um princípio de sistematização do comercio, da moradia e de todas as circulaçóes necessárias sobre o território urbano: o exemploda cidade de Richelieu, na França.Foucault a descreve como uma cidade "construída a partir de nada" e que "utilizou-se a célebre forma do acampamento romano que, na época, acabava de ser reutilizada na instituição militar como instrumento fundamental de disciplina" (FOUCAULT, 2008, p.23): uma unidade modular "microcósmica" era capaz de organizar a cidade em sua totalidade. Através de um elemento arquitetônico bem definido, combinando-se entre si e com estruturas de circulação determinadas pelas vias de calibres distintos, organizou-se uma relação bastante rígida de ocupação e de distribuição, valendo-se dos mesmos princípios hierárquicos para determinar as formas de morar, de habitar, os locais de trocas, de reuniâo, das relaçóes mais elementares do cotidiano de uma cidade.

Graham fornece reflexóes semelhantes quando escreve em 1978 seu texto "Essay on Video, Architecture and Television", discutindo os efeitos perceptivos e sociais promovidos por elementos arquitetônicos, a relação entre revelar e esconder, visão e corpo, ou ainda entre o Funcionalismo e o Capitalismo. Nele, Graham analisa a arquitetura como um meio decisivo para a construção do espaço em um sentido social e culturalmente definido, permitindo indagaçóes que cercam a tensão entre 'códigos arquitetônicos versus códigos sociais'.

Os dois últimos tópicos definidos por "O Uso do Vidro nas Vitrines / Mercadorias nas Vitrines" e "Construçóes de Vidro: 'Vitrines' das Corporaçôes" resumem bem este raciocínio. Elas apontam para como uma ação objetiva (a construção do dispositivo da vitrine e da fachada de vidro) guarda um significado subjetivo completado com a confrontação do observador: as disposiçóes que a vitrine estabelece entre cada elemento envolvido no desempenho deste aparato arquitetônico (aí incluso o próprio observador, juntamente com sua imagem projetada sobre a mercadoria exposta) respondem a uma funçáo que marca as relaçóes de troca e de consumo dominantes nas cidades contemporâneas. Os efeitos óticos disparados pela reflexão e a dimensão do ego que define a confrontação da própria imagem, associada ao forte sentido social que a barreira física do vidro implica(separando corpos e espaços) intermedia a sua presença, projetando em seu inconsciente um estado de ilusão em que a mercadoria exposta atinge uma condiçáo de síntese de sua própria representaçáo.Estes dispositivos, afirma Graham, atuam 


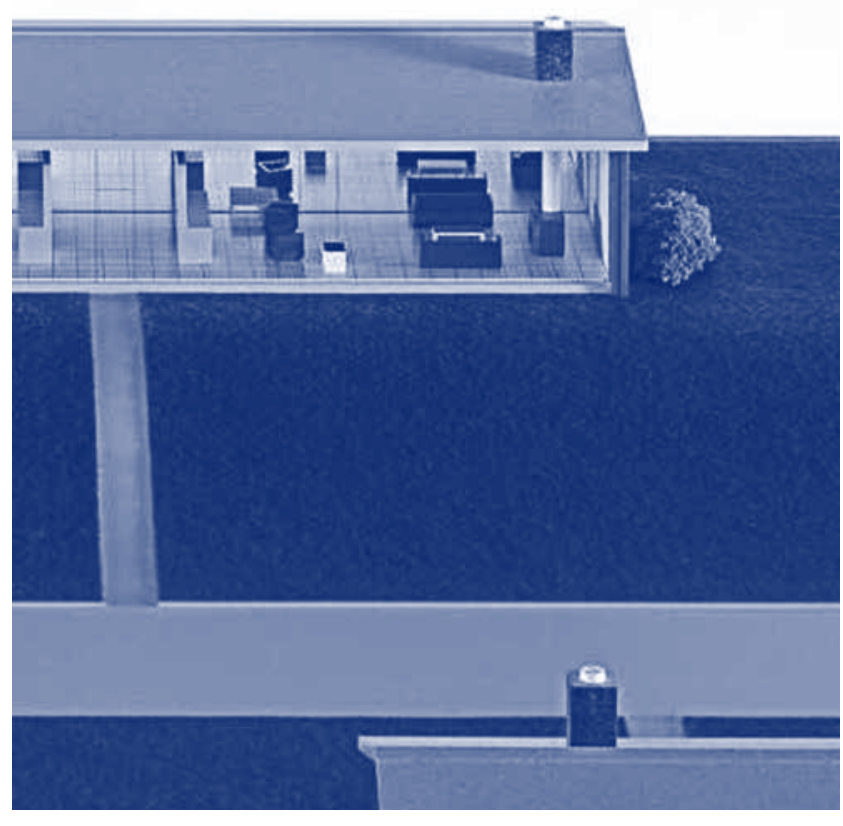

Figura 2: Alterations to a Suburban House, 1978.

"eficientemente empreendendo os desejos latentes do passante casual, para conferir um significado subjetivo pré-determinado sobre os bens que este 'objetivamente' coloca sobre o que está sendo visto" (GRAHAM, 1999, p.58).

Importante notar a cidade e seus elementos constitutivos sendo tomados como meio específico e origem de questôes, quando aspectos e significados espaciais dominarão as propostas de Graham, enfocando as formas e os mecanismos pelos quais os componentes, elementos, dispositivos e outros recursos arquitetônicos e/ou espaciais incidem sobre a experiência dos espaços e situaçóes confrontadas no cotidiano das cidades.

Destacam-se duas obras: Video Piece for Shop Windows in na Arcade e Alterations to a Suburban House, ambas de 1978. A primeira previa uma intervenção sobre vitrines de duas lojas de departamento em uma galeria comercial, articulando planos espelhados, câmeras e monitores de vídeo. Graham buscava intervir nos mecanismos de percepçáo ativados pelo dispositivo visual da vitrine, rearticulando o processo de apreensão e interação em que o observador é envolvido e revelando-a enquanto elemento mediador e simbólico para um "estado de alienação e incompletude" entre mercadoria e a consciência do consumidor (COLOMINA; FRANK; PELZER, 2001, p. 57).

Alterations to a Suburban House consistia em um modelo apresentando uma proposta de intervenção em uma típica residência dos subúrbios norte-americanos: substitui-se a fachada em alvenaria por um imenso pano de vidro, abrindo para a rua a visão da sala de estar como algo semelhante a uma vitrine; ao mesmo tempo, um espelho instalado ao fundo desta mesma sala, paralelo ao plano de vidro, traz para dentro da intimidade do lar a presença do espaço externo. Graham explora a integraçáo dos espaços interno e externo definidas por essa configuração arquitetônica específica, pondo em questão o estilo de vida dos subúrbios americanos através de tensôes entre níveis socialmente aceitos na relação entre público e privado, inclusão e exclusão e, no limite, entre sociedade/cidade/paisagem.

O que as obras de Graham informam é a capacidade de identificar na própria materialidade dos elementos e dos componentes que constroem o espaço, nas com que este se apresenta, as relaçóes subjetivas que acabam determinando a condiçáo do público e a partir daí toda ordem de relaçóes sociais decorrentes: os efeitos perceptivos e sociais promovidos por elementos arquitetônicos, a relação entre revelar e esconder, visão e corpo.

Neste sentido, o longo e diversificado processo de investigação sobre os modos de recepção do objeto de arte conduziram Graham ao desenvolvimento de uma proposta que, em última instância, figura como uma problematizaçáo de dispositivos estabelecendo formas, mecanismos e procedimentos de poder.O que permitedizer que, às análises e reflexôes promovidas por Foucault, Graham traz uma complementaçáo: promove formas muito próximas de abordagem dos dispositivos, porém, através de suas dimensôes formais e materiais - procedimento intrínseco à produçáo de arte. No limite, sua prática artística representa outras formas e outros processos de inserção dentro de uma realidade constituída por camadas de complexos significados simbólicos, políticos e ideológicos.

\section{References}

COLOMINA, B.; FRANK, M.; PELZER, B. (2001). Dan Graham. New York: Phaidon.

FOUCAULT, M. (2006). O poder psiquiátrico: curso dado no College de France (1973-1974). São Paulo: Martins Fonte.

FOUCAULT, M. (2008). Segurança, território, população: curso dado no College de France (1977-1978). São Paulo: Martins Fontes.

GINTZ, C. (1994, May). Beyond the looking glass. Art in America, 5, 84-98.

GRAHAM, D. (2009). El arte con relación al arquitectura. La arquitectura com relación al arte. Barcelona: Gustavo Gili.

GRAHAM, D. (1999). Essay on Video, Architecture and Television. In ALBERRO, A.; GRAHAM, D. (Eds.), Two-Way Mirror Power: Selected

Writings by Dan Graham on his Art (pp. 52-61). Boston: The MIT Press.

GRAHAM, D. (1990, May/Jun). Dan Graham. Flash Art, 152, 142-144.

GRAHAM, D. (1981, December). Not-post Modernism: History Agaisnt Historiscm, European Archetypal Vernacular in Relation to American Commercial Vernacular, and the City as Opposed to the Individual Building. Artforum, 50-58.

KWON, M. (2004). One place after another: Site-Specific Art and Locational Identity. Boston: The MIT Press. 